\title{
GLOBAL BITCOIN MARKETS AND LOCAL REGULATIONS
}

Cyn-Young Park, Shu (Grace) Tian, and Bo Zhao

NO. 605

January 2020
ADB ECONOMICS
WORKING PAPER SERIES

$\mathrm{ADB}$ 


\section{ADB Economics Working Paper Series}

\section{Global Bitcoin Markets and Local Regulations}

Cyn-Young Park, Shu (Grace) Tian, and Bo Zhao

No. 605 | January 2020
Cyn-Young Park (cypark@adb.org) is a director from the Regional Cooperation and Integration Division, Shu (Grace)Tian (stian@adb.org) is an economist from the Macroeconomics Research Division, and Bo Zhao (zhaobo@gmail.com) is a former economist at the Economic Research and Regional Cooperation Department, Asian Development Bank.

Comments from ADB Chief Economist Yasuyuki Sawada and participants at the 43rd Conference of the Federal of ASEAN Economic Associations (November 2018) are gratefully acknowledged 
(C) 2019 Asian Development Bank

6 ADB Avenue, Mandaluyong City, 1550 Metro Manila, Philippines

Tel +632 8632 4444; Fax +63286362444

www.adb.org

Some rights reserved. Published in 2019.

ISSN 2313-6537 (print), 2313-6545 (electronic)

Publication Stock No. WPS200006-2

DOI: http://dx.doi.org/10.22617/WPS200006-2

The views expressed in this publication are those of the authors and do not necessarily reflect the views and policies of the Asian Development Bank (ADB) or its Board of Governors or the governments they represent.

ADB does not guarantee the accuracy of the data included in this publication and accepts no responsibility for any consequence of their use. The mention of specific companies or products of manufacturers does not imply that they are endorsed or recommended by ADB in preference to others of a similar nature that are not mentioned.

By making any designation of or reference to a particular territory or geographic area, or by using the term "country" in this document, $A D B$ does not intend to make any judgments as to the legal or other status of any territory or area.

This work is available under the Creative Commons Attribution 3.0 IGO license (CC BY 3.0 IGO)

https://creativecommons.org/licenses/by/3.0/igo/. By using the content of this publication, you agree to be bound by the terms of this license. For attribution, translations, adaptations, and permissions, please read the provisions and terms of use at https://www.adb.org/terms-use\#openaccess.

This CC license does not apply to non-ADB copyright materials in this publication. If the material is attributed to another source, please contact the copyright owner or publisher of that source for permission to reproduce it. $\mathrm{ADB}$ cannot be held liable for any claims that arise as a result of your use of the material.

Please contact pubsmarketing@adb.org if you have questions or comments with respect to content, or if you wish to obtain copyright permission for your intended use that does not fall within these terms, or for permission to use the ADB logo.

Corrigenda to ADB publications may be found at http://www.adb.org/publications/corrigenda.

Notes:

In this publication, “\$” refers to United States dollars.

ADB recognizes "China" as the People's Republic of China.

The ADB Economics Working Paper Series presents data, information, and/or findings from ongoing research and studies to encourage exchange of ideas and to elicit comment and feedback about development issues in Asia and the Pacific. Since papers in this series are intended for quick and easy dissemination, the content may or may not be fully edited and may later be modified for final publication. 


\section{CONTENTS}

TABLES AND FIGURES

ABSTRACT V V V v

$\begin{array}{lll}\text { I. INTRODUCTION } & 1\end{array}$

II. LITERATURE REVIEW AND CONTRIBUTION OF THE STUDY 3

III. $\quad$ BACKGROUND $\quad 6$

IV. METHODOLOGY

A. Data 10

B. Empirical Model 11

C. Results 13

V. CONCLUSION AND POLICY IMPLICATIONS 19

$\begin{array}{ll}\text { REFERENCES } & 21\end{array}$ 


\section{TABLES AND FIGURES}

\section{TABLES}

$1 \quad$ Regulation Events 10

2 Descriptive Statistics 12

3 Effects of Regulation Events on Local Bitcoin Price 14

$4 \quad$ Effects of Regulation Events on Local Bitcoin Trading Volume 16

5 Effects of Financial Openness 18

\section{FIGURES}

$1 \quad$ History of Bitcoin Price, 1 October 2013-31 May 2018

$2 \quad$ Bitcoin Trading Volume in Different Markets, January 2013-January 2018

$3 \quad$ Share of Bitcoin Trading Volume in Different Markets, January 2013-January $2018 \quad 7$

$4 \quad$ Bitcoin Prices in Six Major Markets 8

5 Bitcoin Trading Volumes in Six Major Markets 9

6 Cumulative Average Abnormal Return after the Regulation Events 15

7 Cumulative Average Abnormal Volume after the Regulation Events 17 


\begin{abstract}
Since the launch of Bitcoin in 2009, the spectacular rise and fall of cryptocurrencies and the underlying blockchain technology have attracted global attention. While the application of distributed ledger technology presents great economic and business potential, significant volatility and speculative trading of cryptocurrencies have raised concerns over investor and consumer protection and prompted government interventions within their respective jurisdictions. This study focuses on the six Bitcoin trading markets comprising $99 \%$ of global trading volume as of February 2018. Adopting the event study methodology to newly compiled information about local regulation events, we find that the effect of government regulations on the Bitcoin price is only short-lived, but regulations discourage trading activities for a longer term in local markets. Interestingly, however, the repressive effect of domestic regulations on trading activities can be mitigated by the domestic financial market openness. Together, these findings are consistent with the view that Bitcoin markets are globally integrated and that, to uphold market integrity, international cooperation would be essential.
\end{abstract}

Keywords: Bitcoin, cryptocurrency, financial market openness, international cooperation, regulation

JEL codes: E61, G10, G14, G18 


\section{INTRODUCTION}

Since the launch of Bitcoin in 2009, the spectacular rise and fall of cryptocurrencies and the underlying blockchain technology have attracted global attention. During 2017, the price of Bitcoin and other cryptocurrencies increased dramatically before falling steeply in 2018. As one of the first products employing distributed ledger technology, Bitcoin has sparked considerable controversy among investors, policy makers, and researchers over its potential as a possible substitute for currency or simply its asset nature as a commodity.

As the price of Bitcoin fluctuated sharply in recent years, with the largest daily change of $17 \%$ between 2017 and 2018, many national authorities and regulatory agencies started to regulate the local Bitcoin market through either communication or direct intervention amid concern over speculative investor hysteria and its implications for financial stability. Meanwhile, observers debate whether regulators should intervene and, if so, what approaches would be appropriate given a major tradeoff between protecting investors and encouraging financial innovation.

An increasing number of countries have become concerned about the risks, particularly those associated with nonsovereign cryptocurrencies. Cryptocurrencies, such as Bitcoin, are "mined", scarce, with limited supply, and uncontrolled by any central political authority (Al-Khazali, Elie, and Roubaud 2018). 'Bitcoin has no intrinsic value and the rapid rise in its price may have been purely speculative. But can this justify strict regulation? Financial regulators and policy makers should ensure that trading occurs in an organized manner and investors are protected against manipulation. But beyond that, unless the cryptocurrency poses a systemic risk or a threat to financial stability, the rationale for regulation remains weak. And regulatory effectiveness is yet another issue. Because national regulators can only regulate cryptocurrency within their own jurisdictions dominated by their fiat currencies, the decentralized nature of Bitcoin formation and trading pose a challenge to the national regulators in how to curb speculative investor behaviors from nondomestic markets in the global Bitcoin network (Böhme et al. 2015).

Globally, most Bitcoin trading volume is in six markets denominated by major currencies: the United States (US) dollar, yuan, won, yen, euro, and pound sterling. Although the traded asset is homogeneous, Bitcoin prices vary across different markets, driven by market friction, including institutional factors, information asymmetry, transaction costs, and so on. (Merton 1987, Shleifer and Vishny 1997, DeLong et al. 1990, and Grobm and Vayanos 2002)

Because market friction limits arbitrage opportunities across different markets, the prices of the Bitcoin in individual markets may differ from each other although the crypto assets being traded are identical. Market frictions lead to market segmentation to a certain extent, where each market forms its respective pricing dynamics subject to local market demand and supply. When a market introduces a regulation or signals an authority stance in the form of communication, local trading may be affected, and local price dynamics could be influenced. While the impact on equity and bond prices of public information such as regulation, macroeconomic data releases, and political events has been extensively documented in the literature (Gilbert et al. 2017; Hansen and McMahon 2016; Gau and Wu 2017; Frijns, Indriawan, and Tourani-Rad 2015; Even-Tov 2017; Bernanke and Kuttner 2005; Verrecchia 2001), no such evidence is documented in the Bitcoin market.

\footnotetext{
"Mining" is essentially the acquisition and creation of cryptocurrency, such as bitcoin, as a way to introduce more coins into the system, as rewards for doing computational work.
} 
Figure 1: History of Bitcoin Price, 1 October 2013-31 May 2018

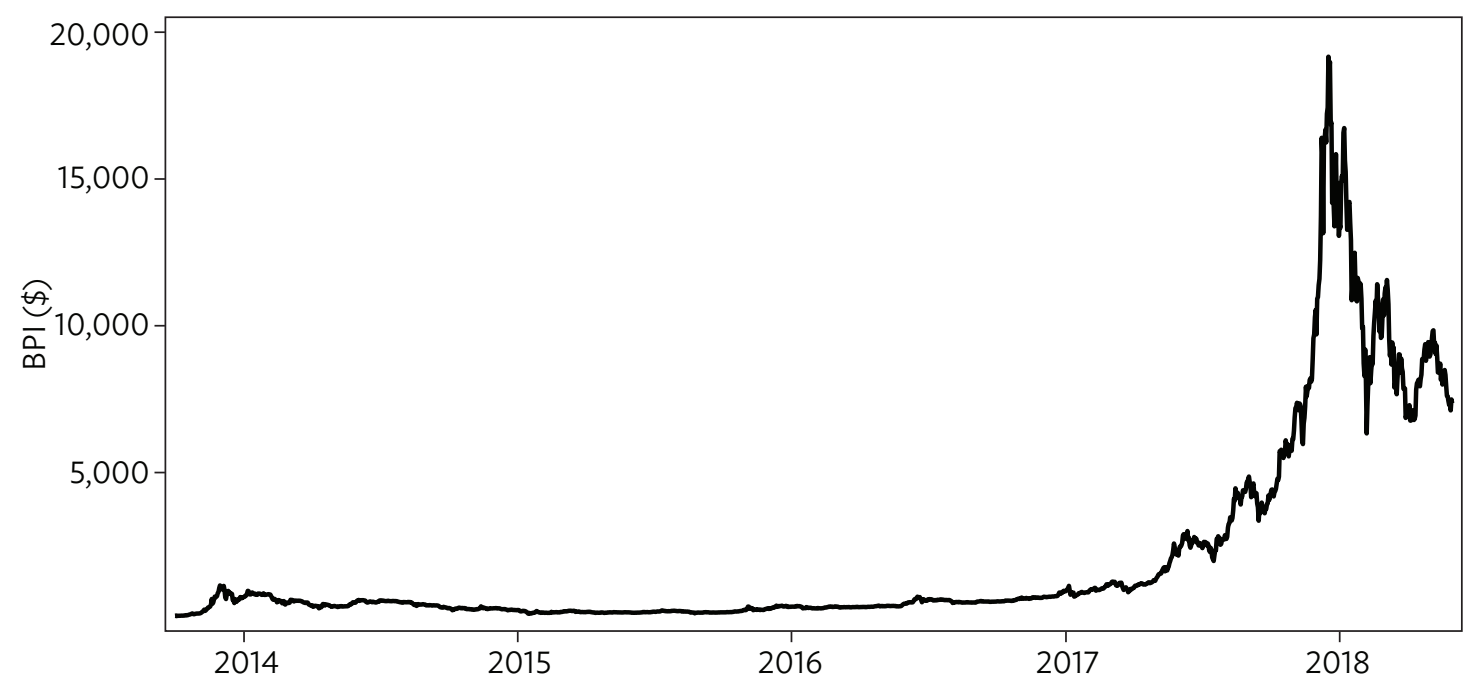

$\mathrm{BPI}=$ Bitcoin Price Index

Source: Coindesk.com

Regulations and related policy announcements would likely affect pricing dynamics, trading behavior, liquidity, and market efficiency in national Bitcoin markets. Yet, given that cryptoassets do not necessarily belong to any single jurisdiction, it is unclear to what extent Bitcoin prices would respond to local market regulations. More specifically, during excessive volatility in Bitcoin markets, many countries have introduced regulation and announcements to curb speculation and prevent illegal and unfair acts in cryptocurrency trading. However, how effective local market regulation is in guiding the Bitcoin market and to what extent such individual market regulation will affect Bitcoin prices and trading activity in different jurisdictions remain unanswered questions. To understand these questions, this study tests the theoretical implications on how market frictions caused by local regulations will lead to discrepancies in prices of an identical assets in global markets.

By examining the regulations and market reactions to these regulatory events across markets, this study aims to answer the following questions:

(i) Is local regulation effective in guiding price dynamics and trading activity in Bitcoin markets that are global in nature?

(ii) How integrated is the global Bitcoin market? If market frictions caused by local regulations have lasting impact on national Bitcoin prices, a significant degree of market segmentation must exist in cross-border trading of Bitcoin worldwide.

(iii) If global Bitcoin markets are segmented, what other potential factors may contribute to it? Do other factors, such as financial market development, market depth and liquidity, and financial openness affect the effectiveness of regulations on national Bitcoin markets? 
With new evidence, we reveal policy implications for regulatory effectiveness in global Bitcoin markets. We can examine whether national regulators have effective tools to govern Bitcoin markets that trade globally to protect investors and safeguard financial stability. The results shed light on how national regulators can collaborate for a more harmonized approach across jurisdictions to foster the healthy development of the cryptocurrency market.

Knowledge about the Bitcoin market can be broadly divided into three groups. One group of studies tries to understand the nature of cryptocurrencies, while another investigates the factors that may determine the cryptocurrency price. The third group investigates market friction that may cause individual market price discrepancies among Bitcoin markets across jurisdictions. For example, Pieters and Vivanco (2017) and Viglione (2015) both document that Bitcoin prices vary across individual markets and suggest that market attributes caused the price differences across jurisdictions dominated by different fiat currencies. Nevertheless, since regulators can only intervene in Bitcoin trading in their own jurisdictions, our study extends Pieters and Vivanco (2017) and Viglione (2015) by investigating how shocks in the form of individual market regulations would influence local and international Bitcoin markets.

Using 12 regulations issued by the six major Bitcoin markets from 28 April 2013 to 12 February 2018, we examine relative price reactions to individual markets' regulations over the benchmark global Bitcoin index. We find that Bitcoin prices drop where local market regulations have been introduced. This was a short-term drop in cumulative abnormal return lasting for 1-2 days following a regulation event announcement. However, the abnormal price pattern disappears from the third day onward. Such price movement indicates that local regulation may only have a short-lived impact on the local Bitcoin price. This is intuitive, as the Bitcoin price is determined in a global peer-to-peer trading network, which offers cross-border arbitrage opportunities. But this does not necessarily mean that a regulation event has no impact at all. Further examination indicates that trading activities are significantly influenced by local market regulation events. In particular, a long-term decline in trading volume is documented following the introduction of local regulations, but the magnitude of this repressive effect is smaller in a country with higher financial openness.

The evidence found in this study supports the arguments in Pieters and Vivanco (2017) and Viglione (2015) that local market regulation is a key factor that triggers market friction in global Bitcoin transactions. This study further suggests that, despite market friction, the global Bitcoin market remains highly integrated. Short-term price discrepancies across individual markets may arise through local regulations that influence investors' trading strategies and activity. Since local market regulations become less effective after a very short time, our evidence implies that global Bitcoin markets are not as segmented. This study also implies that international cooperation would be needed to tackle speculative trading in the Bitcoin markets while preventing fraud and potential risks to financial stability.

In this study, section II reviews the research on the Bitcoin market. Section III provides the background on Bitcoin and its regulations. Section IV describes the sample construction and research design. Section $\mathrm{V}$ documents empirical findings and section VI concludes with policy implications.

\section{LITERATURE REVIEW AND CONTRIBUTION OF THE STUDY}

In the literature, Bitcoin is largely documented as an investment instrument rather than as a currency. A European Central Bank board member noted that cryptocurrencies do not qualify as a currency and banks should separate virtual currency business from other trading and investment activities they do 
(Canepa 2018). The Bank for International Settlements also argued that cryptocurrencies are unable to sustain a monetary system and may not be considered as a currency (Tahir 2018). In particular, Yermack (2013) examines the three functions of a typical currency: value storage, medium of exchange, and account unit. He argues that Bitcoin, which features speculative trading, excessive volatility, low liquidity, cyber security issues, large unit price, limited payment options, as well as low correlation with conventional currency and gold, behaves like a speculative asset rather than a currency.

Nonetheless, although Bitcoin lacks validity as a currency, some studies note other potential functions, such as a hedge and safe haven against global shocks. Bouoiyour and Selmi (2015) investigate a set of potential determinants of Bitcoin prices over the short and long run, and argue that Bitcoin behaves more like a speculative asset than a hedging asset like gold. However, Dyhrberg (2016a) indicates that Bitcoin and gold share similarities in that they have no nationality, are mined, and are globally standardized. Dyhrberg (2016a, 2016b) provides empirical evidence that Bitcoin prices display risk-hedging properties like gold and it can be used as hedge against shocks in stock and currency markets in the short term. Bouri, Molnár, Azzi, Roubaud, and Hagfors (2017) show that Bitcoin may serve as a safe-haven asset for Asian stocks, but do not show effective hedge capacity for major global stock, bond, oil, gold, and commodity indexes as well as a US dollar index. Moreover, the hedging property is sensitive to investment horizons. Bouri, Gupta, Kumar Tiwari, and Roubaud (2017) further decompose Bitcoin returns across different investment horizons indicating that the cryptocurrency shows hedging properties against global uncertainties captured by the Chicago Board Options Exchange Volatility Index and can be used in short-term hedging. Overall, the hedging capacity of Bitcoin varies across types of risky assets and seems to work over a short horizon. Nevertheless, research shows that Bitcoin serves as a suitable diversifying asset (Bouri, Molnár, Azzi, Roubaud, and Hagfors 2017; Stavroyiannis 2018).

However, the highly volatile price patterns, which work against Bitcoin's value as a hedge and safe-haven commodity, have invited interest in understanding pricing formation in the Bitcoin market. For instance, Ciaian, Rajcaniova, and Kancs (2016) explore the determinants of Bitcoin prices using three sets of pricing factors: supply-demand forces, investment attractiveness, and macroeconomic and financial conditions. They find that supply-demand forces and investment attractiveness have a significant impact on the Bitcoin price, but these impacts decrease during the more recent sample period, and macroeconomic and financial factors overall have a weaker impact on Bitcoin prices, especially in the long run. Balcilar et al. (2017) analyze the impact of trading activities on Bitcoin returns and volatility and show the predictive ability of trading volume in future Bitcoin performance. Urquhart (2017) finds evidence of Bitcoin price clustering and shows that the price clustering is positively affected by the level of Bitcoin price and trading volume. But Blau (2018) argues that speculative trading does not seem to be related to the huge swings in Bitcoin price and the high volatility in the Bitcoin market.

While most studies treat Bitcoin market as a single market, a few studies note the price differentiation of Bitcoin across different markets. Viglione (2015) examines the role of governance quality in individual markets on Bitcoin pricing and finds that, as an international asset, Bitcoin's prices are significantly influenced by the institutional environment of its trading market. In particular, economic freedom is found to significantly lower the premium of Bitcoin in a particular market. Pieters and Vivanco (2017) document significant differences among Bitcoin prices across major markets and attribute such price differentials to market characteristics. They suggest that markets with stricter financial regulations, such as requiring customer identification, tend to deviate from other markets' pricing processes. This strand of studies directly links to the literature, looking at how market friction 
would create price discrepancies for the same assets trading in different markets. Extant knowledge shows that market friction-institutional factors, transaction costs, and information asymmetry-has driven discrepancies among market prices and limited arbitrage (see Merton 1987, Shleifer and Vishny 1997, DeLong et al. 1990, and Grobm and Vayanos 2002, among others).

While Viglione (2015) and Pieters and Vivanco (2017) address how such factors as governance and financial sector regulations drive price discrepancies in different Bitcoin markets, this study extends them by introducing exogenous shocks of regulation announcement, which may form new market frictions, and accessing the impact of these new local market frictions from a market efficiency perspective using event study. After controlling proxies for market friction, the study examines market reaction to various regulations across individual markets. The literature has long established that financial markets react to public information that extensively influences firm valuation, trading volume, market liquidity, and market efficiency (Diamond and Verrecchia 1991, Verrecchia 2001, Leuz and Wysocki 2007, Gao 2008, Kondor 2012). As a form of exogenous public information, regulations will direct investor trading, which will incorporate related information into asset prices. ${ }^{2}$ While the policy reactions of Bitcoin prices have been widely observed, less is known about how the prices of global assets react to regulations in national markets. Thus, this study offers novel evidence on how national regulation may influence Bitcoin prices and trading activity within and beyond the national markets. The evidence also suggests the necessity for regulators across countries to collaborate to foster the healthy development of the cryptocurrency market.

This study is related to earlier studies that explore Bitcoin market efficiency but treat Bitcoin as a single universal market. Urquhart (2016) investigates efficiency in the Bitcoin market, finding that it is inefficient at an early stage but shows some efficiency later. Nadarajah and Chu (2017) document that the Bitcoin market is efficient using a transformed Bitcoin return. Brandvold et al. (2015) investigate the price discovery role of major Bitcoin exchanges and find that large exchanges, such as Mt. Gox, foster price discovery in the Bitcoin market and serve as major information providers. ${ }^{3}$ While this strand of research sheds light on how information is priced and assesses market efficiency in the Bitcoin market, they treat Bitcoin as a universal asset in a single market and ignore the price discrepancy in different individual markets. This paper extends this strand of studies on how different local Bitcoin markets react to local regulation events as external shocks.

Adding to this group of research, our study utilizes exogenous shocks in the form of regulation events in individual Bitcoin markets to understand how Bitcoin prices and trading activities respond to regulation shocks. In particular, we show how national regulations affect actual trading behaviors and perceptions of Bitcoin that are priced in global Bitcoin markets. In doing so, this study extends and contributes to the literature with additional knowledge about pricing discovery across different Bitcoin markets.

2 Other than regulations, typical examples of exogenous public information include macroeconomic data releases (among others, see Flannery and Protopapadakis 2002, Rigobon and Sack 2004, Bernanke and Kuttner 2005), and political events such as US President Donald Trump's election (Wagner, Zeckhauser, and Ziegler 2018).

3 Mt. Gox was launched in July 2010. In February 2014, Mt. Gox suspended trading, closed its website and exchange service, and filed for bankruptcy protection from creditors. 


\section{BACKGROUND}

Cryptocurrencies are digital tokens created, stored, and governed electronically by an open, decentralized cryptography system. Cryptocurrency can be used to exchange fiat currency, to buy certain goods and services, or as an investment vehicle. Over 1,500 cryptocurrencies exist, with a market cap of $\$ 400$ billion as of February 2018, with Bitcoin the largest, representing a third of the market (J.P. Morgan Global Research 2018). Bitcoin combines distributed ledger technology and cryptography in the context of a blockchain with no central issuing authority or physical forms.

Bitcoin uses cryptography to guide encryption protocols that identify ownership and verify transactions (Pieters and Vivanco 2017). It is designed to provide a nonsovereign, permissionless, decentralized trust solution, with security provided through the blockchain structure. As a "permissionless" system, it is open to anyone who downloads the open source software, with the transaction record publicly available. As a decentralized system, there is no single or group of controllers of Bitcoin, but rather all participants are involved in the development and use of the system. Bitcoin also uses the proof-of-work concept to achieve consensus among the nodes, with transaction confirmation through independent users who solve cryptographic problems to generate new blocks evidencing transactions, and these users are in turn paid in newly created Bitcoin (as well as applicable commissions). This process is called "mining." The Bitcoin is designed to an ultimate number of 21 million and once mined, every Bitcoin (or a fraction) can be traded on exchanges operated and accessible 24 hours a day, 7 days a week.

During 2017, the price of Bitcoin and other cryptocurrencies increased dramatically, before falling steeply at the beginning of 2018. Bitcoin and a number of other cryptocurrencies were arguably the focus of one of the largest speculative bubbles in history, with a large volume of mining and trading taking place in Asia. Bitcoins are traded on exchanges dominated by different currencies. Six markets dominated by the US dollar, yuan, won, yen, euro, and pound accounted for more than $99 \%$ of all Bitcoin trading volume during the sample period from January 2013 to January 2018. ${ }^{4}$ Figure 2 depicts total trading volume with major fiat currencies over the full sample period. It shows the yuan has been the dominant currency for global Bitcoin trading, making up more than $88 \%$ of total Bitcoin trading. Figure 3 shows the evolution of the market structure of Bitcoin trading. Since January 2017, the proportion of Bitcoin trading in yuan significantly decreased. This signifies the impact of the initial crackdown of the Government of the People's Republic of China (PRC) and relevant regulatory agency on the initial coin offering market and later the official shutdown of local online exchanges registered and operating in the PRC. Since then, the proportion of US dollar and yen has started to increase, and the US dollar market has become the largest trading market.

Bitcoin is not pegged to the US dollar or other currencies, nor set by any exchange or government. While Bitcoin is a global asset-an asset that is identical globally-local prices of Bitcoin differ across national markets due to various market frictions. Given market friction in international currency and financial markets, cross-border arbitrage can be quite costly to exercise. If an investor wants to exploit the price differences across markets and arbitrage, possible costs could include money transfer costs, bid-ask spread on exchange rates, limits to the minimum or maximum amount in money transfers, time delays, price uncertainty, and commission fees to trade Bitcoin. Moreover, local government regulations and policies would create market friction and discourage arbitrage opportunities.

4 According to CryptoCompare. https://www.cryptocompare.com/ (accessed 1 February 2018). 
Figure 2: Bitcoin Trading Volume in Different Markets, January 2013-January 2018

(\%)

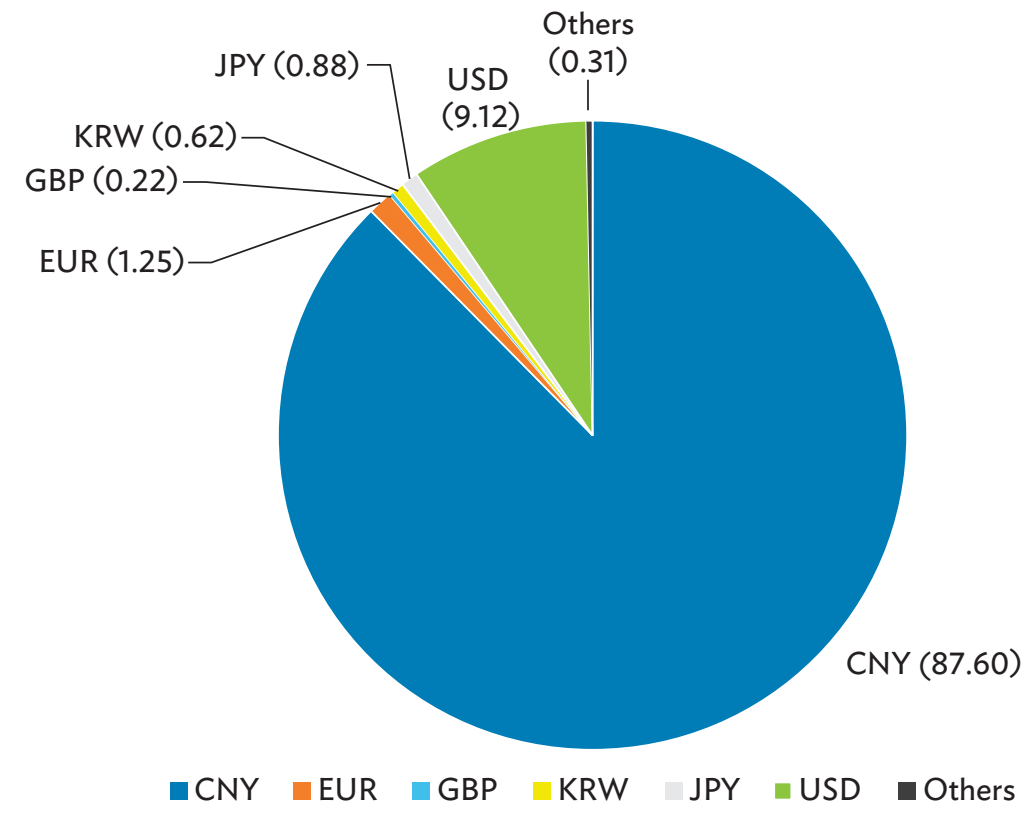

$\mathrm{CNY}=$ yuan, $\mathrm{EUR}=$ euro, $\mathrm{GBP}=$ pound sterling, $\mathrm{KRW}=$ won, JPY = yen, USD = United States dollar. Source: Authors' calculation based on various data sources.

Figure 3: Share of Bitcoin Trading Volume in Different Markets, January 2013-January 2018

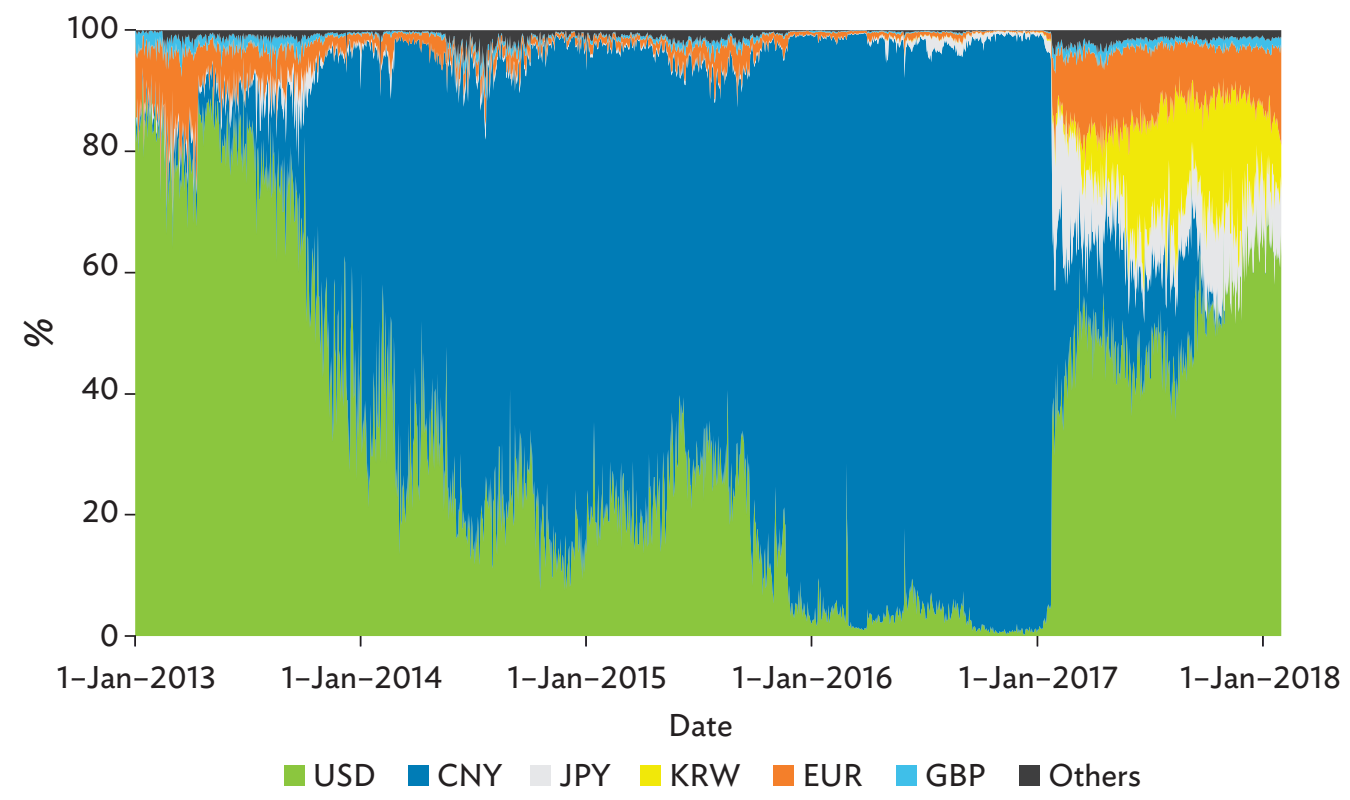

$\mathrm{CNY}=$ yuan, $\mathrm{EUR}=$ euro, $\mathrm{GBP}=$ pound sterling, $\mathrm{KRW}=$ won, $\mathrm{JPY}=$ yen, $\mathrm{USD}=$ United States dollar. Source: CryptoCompare. https://www.cryptocompare.com/ (accessed 1 February 2018). 
Thus, even as Bitcoin is meant to be globally traded as a universal digital asset, its price will be affected by local demand and supply. Different currency denominations in local markets also lead cryptocurrency prices to vary across markets due to frictions and risk premia in foreign exchange markets. In the global Bitcoin market, since cryptocurrency supplies are tightly controlled over the short run, day-to-day variation in the value of cryptocurrencies is mainly driven by changes in local demand and trading conditions for cryptocurrency. In particular, local government regulations and other macroeconomic events may affect investor expectations over the long-term value of cryptocurrency and hence its price.

Figure 4 shows that different Bitcoin markets show different pricing patterns. For instance, a unique "Kimchi premium" seems to exist in the Republic of Korea market, potentially driven by excess demand in the local market. The cross-market price discrepancy is important to understanding the role of market friction and regulations in the Bitcoin markets. As Figure 4 shows, during December 2017 to January 2018, the Bitcoin price was especially volatile in the yuan market, while prices are valued higher in yen and won compared to those in other currencies. Figure 5 shows the variation in trading patterns across major Bitcoin markets. According to Viglione (2015) and Pieters and Vivanco (2017), regulations and institutional quality in local markets contribute to the pricing dynamics in local Bitcoin prices.

While investors' interest in cryptocurrencies as well as the potential of underlying distributed ledger technology has grown massively, policy makers and regulators around the world have become concerned about speculative behavior and associated risks in cryptocurrency, especially from the perspectives of investor protection and financial stability.

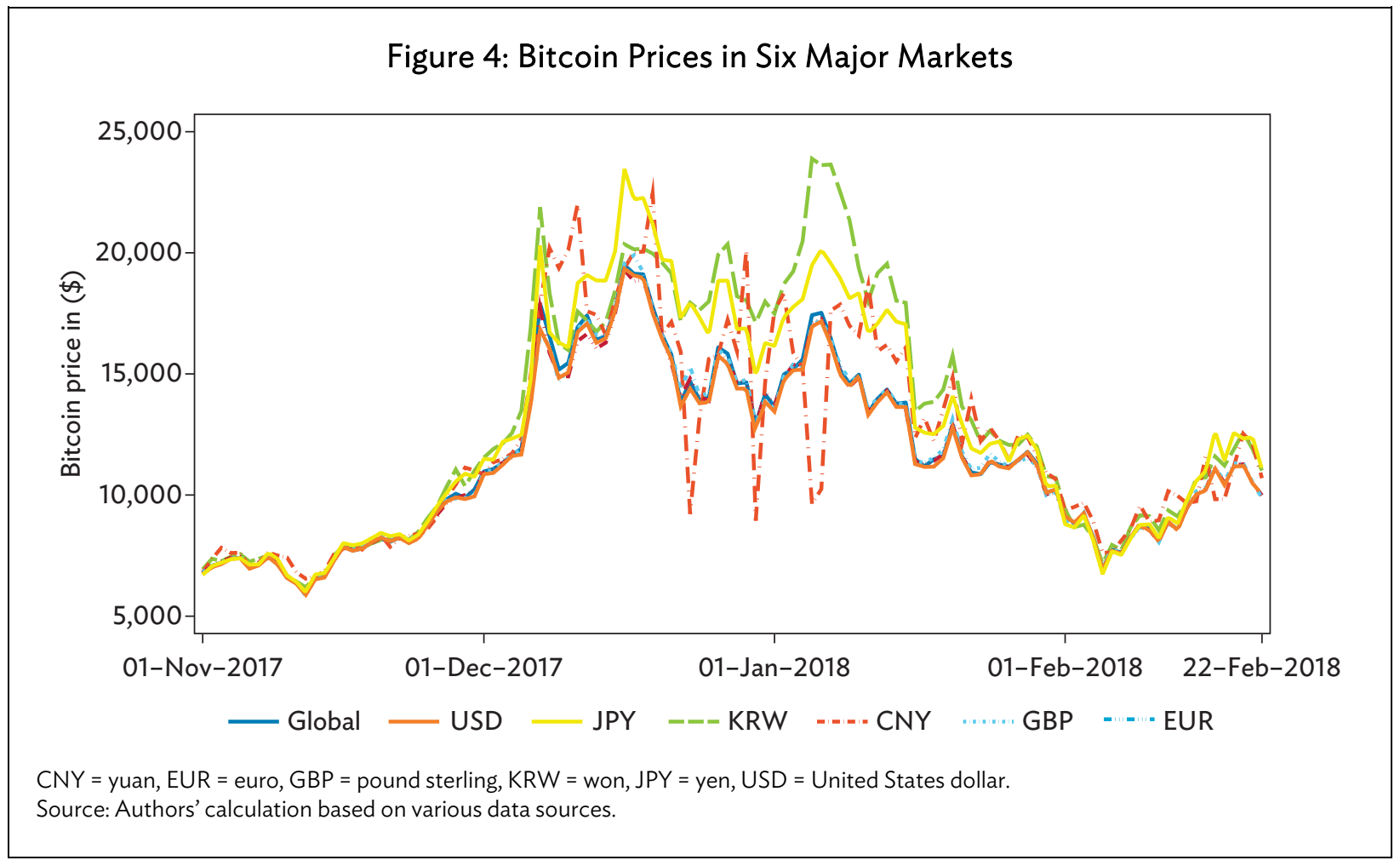




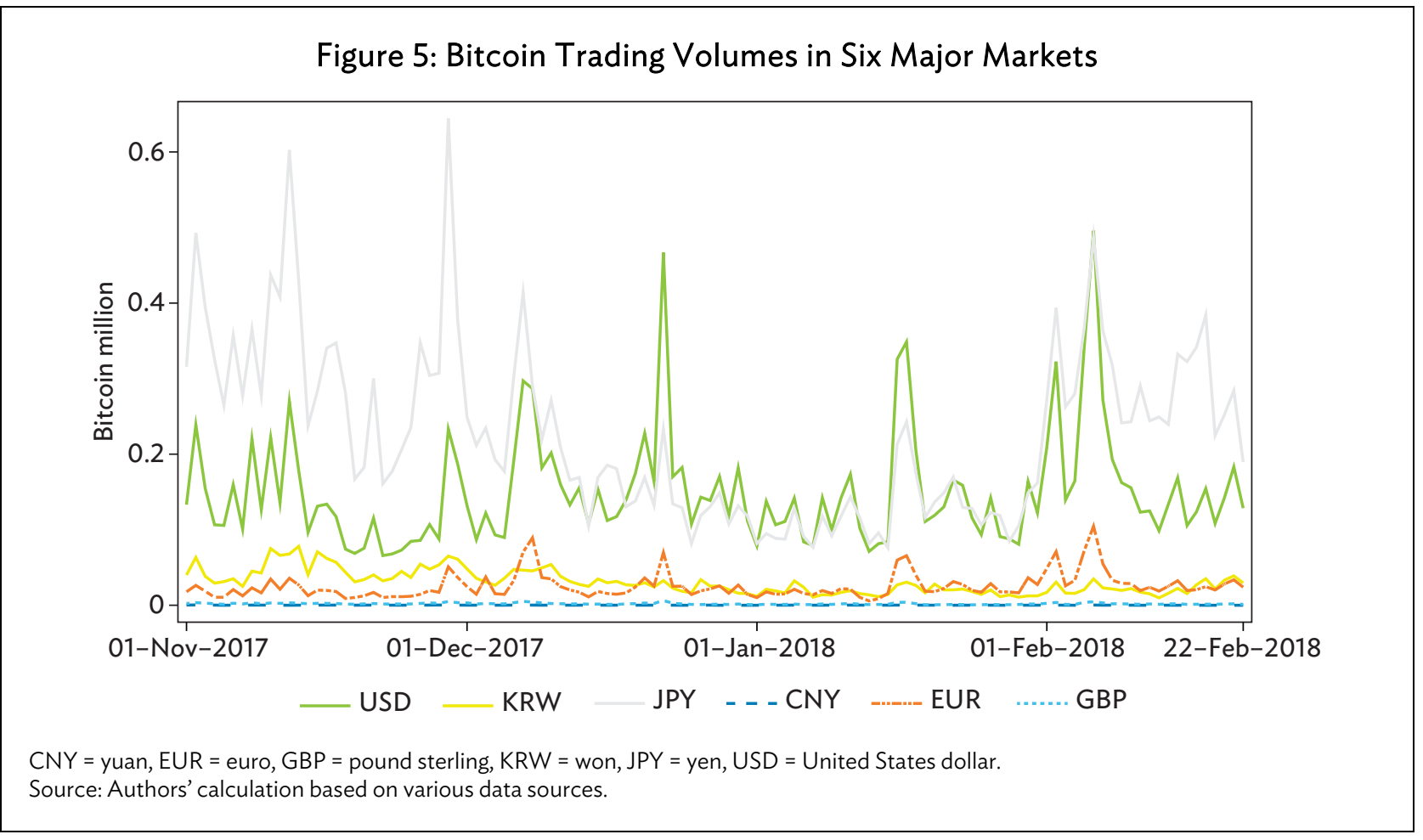

However, regulatory approaches to cryptocurrencies and their applications differ from jurisdiction to jurisdiction. General consensus exists among monetary authorities that cryptocurrency is not a "currency." Perception varies greatly about its potential as a nonsovereign digital token or as an alternative asset class. Without specifying the legal status of digital money, cryptocurrency is in a legal vacuum, and there is no unified approach to dealing with cryptocurrencies. Yet, most governments recognize the potential of the distributed ledger technology behind cryptocurrency, which holds promise to transform financial services and improve financial inclusion. This presents a background for rather cautious regulatory approaches in different jurisdictions not to stifle the growth of innovation and new technology.

Regulators in most jurisdictions have closely monitored developments in the cryptocurrency industry, and experimented with different ways to regulate Bitcoin trading. But at the height of investor hysteria, some made direct interventions. For example, in September 2017, government authorities in the PRC ordered Beijing-based cryptocurrency exchanges to cease trading and immediately notify users of their closure, signaling a widening crackdown by authorities on the industry to contain financial risks associated with the use of cryptocurrencies (Goh 2017). Sometimes the regulators use public communications to warn investors or encourage related innovations. In 2017, the PRC and the Republic of Korea issued outright bans on initial coin offerings. Still others, such as Japan and Singapore, opted for far less radical approaches. Since key questions remain unanswered, causing additional law enforcement issues, it is too early to tell what kind of regulation is right or wrong: the answer depends on the specific situation.

This study offers insights into the degree of market integration for global Bitcoin trading and how investors react to local regulations that create frictions in local transactions of the globally traded Bitcoin. Specifically, the study investigates how government regulations in the form of communications and direct interventions in cryptocurrencies affect local Bitcoin prices and trading volumes and how the price of Bitcoin converges internationally despite local regulations. 


\section{METHODOLOGY}

\section{A. Data}

To answer our research questions, we acquired global Bitcoin price data from coinmarketcap.com, where the global Bitcoin price is calculated by taking the volume weighted average of Bitcoin prices in 393 Bitcoin exchanges. The price unit is in US dollars. Bitcoin prices in six major markets against their fiat currencies-US dollar, won, yen, euro, pound, and yuan-are acquired from cryptocompare.com. The price unit is in the local currency. We use foreign exchange rates of the US dollar against each of the other five currencies to convert all prices to the US dollar. All US dollar exchange rates are from the Federal Reserve System and obtained from 12 noon Eastern Daylight Time (4 p.m. Universal Time Coordinated) US dollar buying rates in New York City.

We collected detailed regulation information, including announcing time, regulatory agency, content, and purpose, if any. The cryptocurrency regulation data are mainly from law firm Perkins Coie and cross-checked with various online resources and news releases. Originally, our sample period included 44 events from five countries and one region. We first dropped nonregulation related events, leaving 16 regulation-related events.

To clearly identify the regulation impact, we require that the regulation event windows cannot overlap with each other. The longest event window we examine is $[0,10]$, that is, from the day of regulation announcement to 10 days after. Therefore, we restrict the difference between announcement days to be no less than 11 days. In case of overlapping, we drop both events from our sample. After the filtering, our sample consists of 12 regulation events with event windows long enough before and after. Table 1 lists all regulation events we used to identify the event effects in the five major economies. The euro area does not appear in the table since, after the filtering, there is no regulation event from the euro area left during our sample period.

Table 1: Regulation Events

\begin{tabular}{|c|c|c|c|c|c|}
\hline ID & Event Date & Country & $\begin{array}{l}\text { Local } \\
\text { Currency }\end{array}$ & Type & Brief Content \\
\hline 1 & 25-Apr-2014 & PRC & yuan & Communication & $\begin{array}{l}\text { The PRC warned banks to cease doing } \\
\text { cryptocurrency-related business. }\end{array}$ \\
\hline 2 & 19-Jun-2014 & Japan & yen & Communication & Japan planned not to regulate Bitcoin. \\
\hline 3 & 18-Sep-2015 & US & US dollar & Intervention & The US classified Bitcoin as a commodity. \\
\hline 4 & 24-Feb-2016 & Japan & yen & Intervention & $\begin{array}{l}\text { Japan proposed a legislation that would recognize } \\
\text { virtual currencies as equal to conventional } \\
\text { currencies. }\end{array}$ \\
\hline 5 & 06-Jan-2017 & PRC & yuan & Intervention & The PRC inspected major Bitcoin exchanges. \\
\hline 6 & 01-Apr-2017 & Japan & yen & Intervention & $\begin{array}{l}\text { Japan enacted a new law authorizing the use of } \\
\text { digital currency as a method of payment, } \\
\text { essentially granting it the same legal status as any } \\
\text { other currency. }\end{array}$ \\
\hline 7 & 17-Apr-2017 & UK & $\begin{array}{l}\text { pound } \\
\text { sterling }\end{array}$ & Communication & $\begin{array}{l}\text { The Bank of England governor stated that the } \\
\text { fintech sector did not need the same level of } \\
\text { regulations as banks. }\end{array}$ \\
\hline 8 & 03-Sep-2017 & PRC & yuan & Intervention & The PRC banned initial coin offerings. \\
\hline
\end{tabular}

continued on next page 
Table 1 continued

\begin{tabular}{|c|c|c|c|c|c|}
\hline ID & Event Date & Country & $\begin{array}{l}\text { Local } \\
\text { Currency }\end{array}$ & Type & Brief Content \\
\hline 9 & 15-Sep-2017 & PRC & yuan & Intervention & The PRC shut down all cryptocurrency exchanges. \\
\hline 10 & 30-Sep-2017 & Japan & yen & Intervention & $\begin{array}{l}\text { Japan granted its first licenses for cryptocurrency } \\
\text { exchanges. }\end{array}$ \\
\hline 11 & 20-Nov-2017 & PRC & yuan & Communication & $\begin{array}{l}\text { The governor of the People's Bank of China said in } \\
\text { an economic forum that people are free to } \\
\text { participate in the Bitcoin market. }\end{array}$ \\
\hline 12 & 28-Dec-2017 & $\begin{array}{l}\text { Republic } \\
\text { of Korea }\end{array}$ & won & Communication & $\begin{array}{l}\text { The Republic of Korea planned to shut down } \\
\text { cryptocurrency exchanges. }\end{array}$ \\
\hline
\end{tabular}

PRC = People's Republic of China, UK = United Kingdom, US = United States. Source: Authors' summary based on various data sources.

To control for financial market friction, depth, and openness in each market in our sample, we also collected daily gold price data in local currency from Bloomberg, foreign exchange rate indices from the Bank for International Settlements, M2 data from International Financial Statistics (IFS) from International Monetary Fund database, gross domestic product (GDP) data from the World Bank national accounts data database, and Bitcoin trading volume data from CryptoCompare.com. ${ }^{5}$

\section{B. Empirical Model}

We employ the event study methodology to investigate the impact of regulations on local market Bitcoin prices and trading volumes. We take the announcement time of the regulations as the event time, and examine whether Bitcoin prices after these events display abnormal returns (i.e., returns in excess of expected returns) and abnormal trading volumes (i.e., trading volumes in excess of expected trading volumes).

The abnormal return is calculated as the difference between the Bitcoin return in a certain single market on a day and the benchmark global return on the same day. The benchmark global return is calculated using the global price index, which is the volume weighted average of Bitcoin prices in 393 Bitcoin exchanges. Our return premium is defined similarly to Viglione (2015).

$$
A R_{i t}=R_{i t}-\hat{R}_{i t}
$$

where $A R_{i t}$ is the abnormal return for Bitcoin on day $t$ in market $i, R_{i t}$ is the daily return on Bitcoin on day $t$ in local market $i, \hat{R}_{i t}$ is the benchmark global Bitcoin return on day $t$ in local market $i$.

Since there is no benchmark global trading volume, we calculate the abnormal trading volume as the difference between the Bitcoin trading volume in a certain local market on day $t$ and the average trading volume in the same market during the previous 5 days from $t-5$ to $t-1$, that is, the estimation window.

5 All data are accessed on 23 February 2018. 
The cumulative abnormal return (CAR) is calculated to measure the aggregate effect on the abnormal returns during the event window, that is, the days around the announcement day 0 . We examine several different event windows: $[0],[0,1],[0,2],[0,5]$ and $[0,10]$. Similarly, we calculate the cumulative abnormal volume $(C A V)$ around the same event windows.

Using the cumulative abnormal return and cumulative abnormal volume as dependent variables, we then run regressions on two key independent variables. local $_{i t}$ is a dummy variable with 1 indicating that the regulation is a local event. Communication $n_{i t}$ is a dummy variable with 1 indicating that the regulation event is in the form of regulatory communication (versus direct intervention).

$$
Y_{i t}=\text { local }_{i t}+\text { Bommunication }_{i t}+\gamma \text { Controls }_{i t}+\varepsilon_{i t}
$$

where dependent variables $Y_{i t}$ represents $C A R_{i t}$ being the cumulative abnormal return or $C A V_{i t}$ being cumulative abnormal volume on day $t$ in local Bitcoin market $i$. Independent variable local $_{i t}$ is a dummy variable equal to 1 when a regulation is announced in local market $i$ on day $t$, Communication $_{i t}$ is a dummy variable equal to 1 when a regulatory communication (versus direct intervention) is made in local market $i$ on day $t$, Controls $s_{i t}$ are control variables that may cause the difference in Bitcoin return or trading volume in different markets, which include: (i) existing market friction proxied by gold return difference between the local market and the global market during the previous 30 trading days in the local market $i$ on day $t$; (ii) gold price in the local market $i$ on day $t$, which captures the level of investor risk-averse; (iii) average Bitcoin trading volume to capture investor sentiment in Bitcoin market in the local market $i$ on day $t$; (iv) annual foreign exchange rate volatility to capture macroeconomic soundness; (v) M2/GDP ratio to capture monetary stance in the local market; and (vi) Chinn-Ito index to proxy for financial openness in the local market (Chinn and Ito 2006).

Table 2: Descriptive Statistics

\begin{tabular}{|c|c|c|c|c|c|}
\hline Variables & Descriptions & Mean & SD & Min & Max \\
\hline Local regulation & Dummy $=1$ if there is a local regulation & 0.167 & 0.375 & 0.000 & 1.000 \\
\hline $\begin{array}{l}\text { Regulation by } \\
\text { communication }\end{array}$ & $\begin{array}{l}\text { Dummy }=1 \text { if regulation is by communication } \\
\text { (versus direct intervention) }\end{array}$ & 0.417 & 0.496 & 0.000 & 1.000 \\
\hline Gold price & Local daily gold price $(\$ 1,000)$ & 1.266 & 0.054 & 1.140 & 1.325 \\
\hline $\begin{array}{l}\text { Gold return } \\
\text { difference }\end{array}$ & $\begin{array}{l}\text { Prior } 30 \text {-day average (local - global) } \\
\text { gold return }(\%)\end{array}$ & -0.029 & 0.072 & -0.263 & 0.114 \\
\hline FX volatility & Average foreign exchange volatility (2014-2017) & 5.259 & 1.710 & 3.155 & 7.844 \\
\hline M2/GDP ratio & Average M2/GDP ratio $(2014-2016)^{a}$ & 1.233 & 0.479 & 0.668 & 1.922 \\
\hline Chinn-Ito index & Average Chinn-Ito index (2014-2016) ${ }^{a}$ & 1.595 & 1.292 & -1.202 & 2.360 \\
\hline Bitcoin volume & $\begin{array}{l}\text { Aggregated Bitcoin transaction volume } \\
\text { (2014-2017; Bitcoin trillion) }\end{array}$ & 0.144 & 0.263 & 0.001 & 0.724 \\
\hline
\end{tabular}

$\mathrm{FX}=$ foreign exchange rate, $\mathrm{GDP}=$ gross domestic product, $\mathrm{M} 2$ = money supply, $\mathrm{SD}=$ standard deviation.

${ }^{a}$ Data are not available for 2017.

Source: Authors' calculation. 
Data for the variables are collected from multiple sources. Gold prices and exchange rates are collected from Bloomberg, M2/GDP ratio is from Haver, Chinn-Ito index is collected from the ChinnIto website, ${ }^{6}$ and Bitcoin prices and trading volume is from CryptoCompare. ${ }^{7}$ Table 2 summarizes these variables.

\section{Results}

Do regulation events cause abnormal returns and volumes in the local Bitcoin trading market compared to other markets? If so, does the effect of these regulation events last long? Is the effect magnitude related to local financial market attributes? We present three sets of results.

Table 3 reports the first, on the effects of regulation events on local Bitcoin CAR in different event windows. Columns (1) to (5) show that the effect is statistically significant and negative on the announcement day (day 0 ) and the day after (day 1). More interestingly, the regulation impact becomes statistically insignificant on local Bitcoin CAR after day 1 . The results mean that the event announcement has a significant impact on local market Bitcoin prices, but such an impact tends to be short-lived and becomes insignificant from 2 days after the announcement onward.

In columns (6) to (10) of Table 3 we explore the possible different impacts between two types of regulation events, being communication or intervention. The results show that the two types of regulation events do not exert significantly different effects on pricing. The effect of local regulation still stays the same and robust after we add the event type dummy variable.

The pattern is visualized in Figure 6 showing that the regulation events seem to have an initial negative impact on local CARs (not so much on the nonlocal markets and the global market), but the impact diminishes after 2 trading days. In general, the results in Table 3 indicate that local regulation has a short-lived impact on Bitcoin prices, which diminish very soon afterward. This suggests that global Bitcoin markets are well integrated with very short-term arbitrage opportunities across markets.

The Chinn-Ito Index. http://web.pdx.edu/ ito/Chinn-Ito_website.htm.

CryptoCompare. https://www.cryptocompare.com/. 


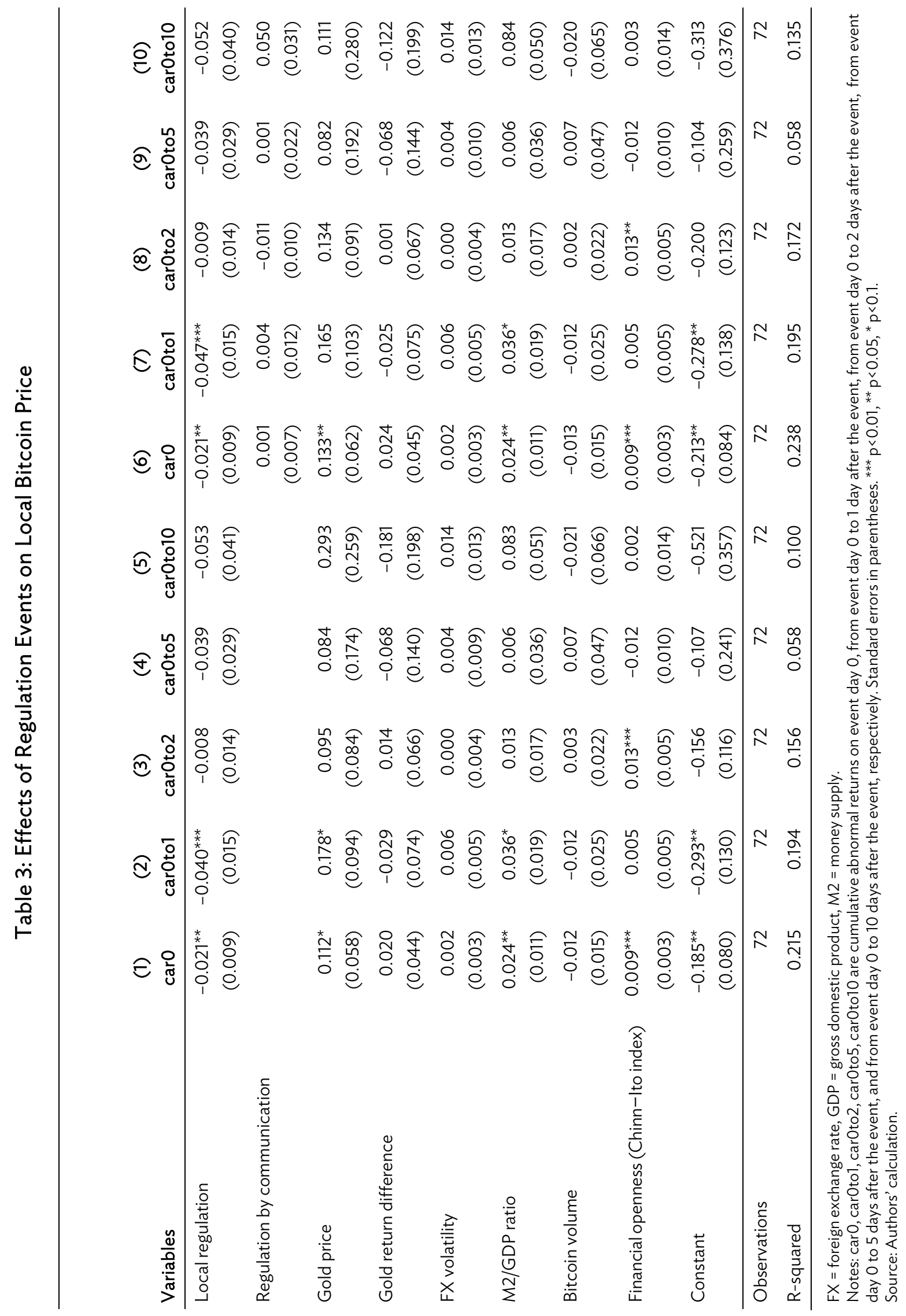


Figure 6: Cumulative Average Abnormal Return after the Regulation Events

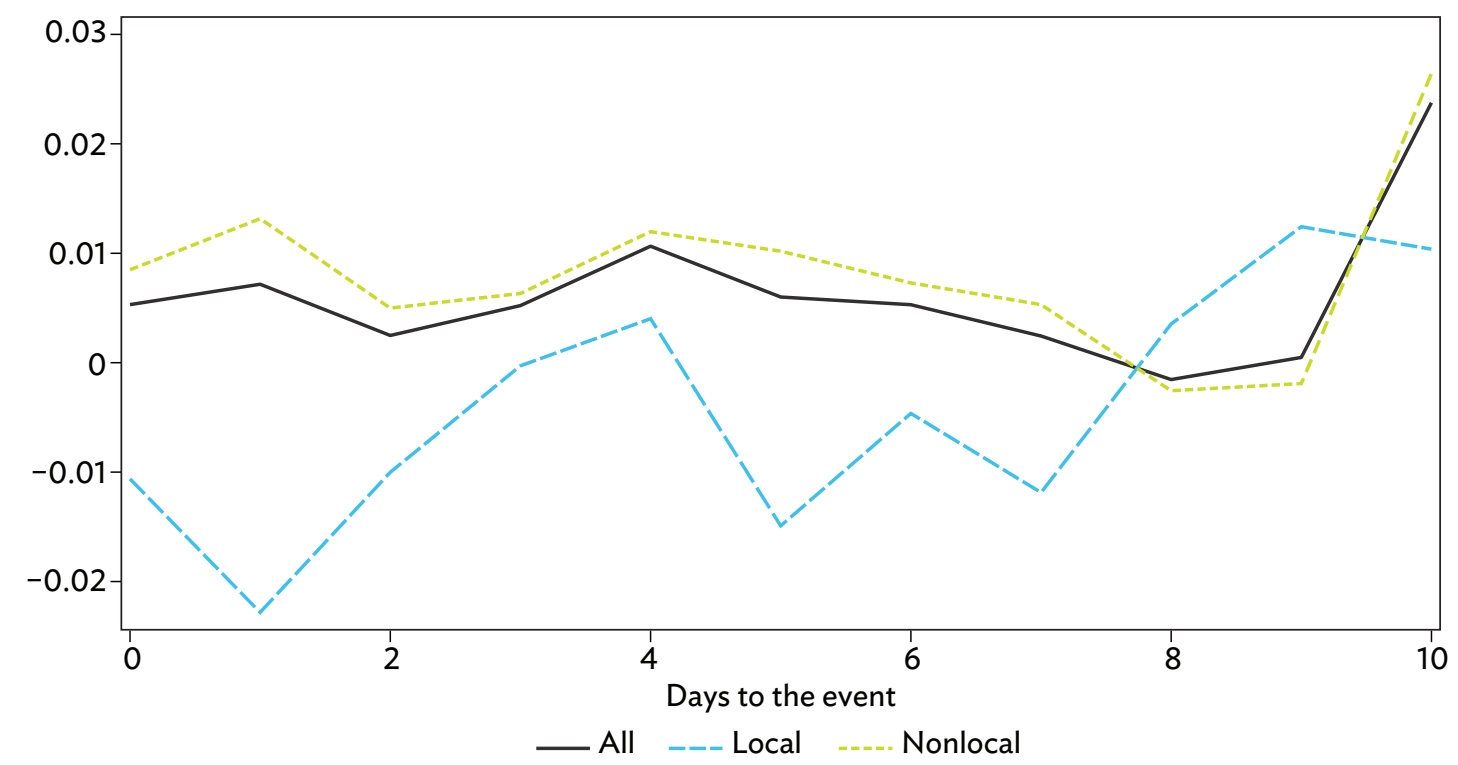

Source: Authors' calculation based on various data sources.

Table 4 reports the second and quite interesting set of empirical results showing the effect of local regulation on CAV. The regulatory impact on trading behavior shows how direct host government action can drive investors out of the country, but cannot effectively control the global demand for Bitcoin and its price. Columns (1)-(5) show that after the announcement of a regulation event, abnormal trading volume increased from day 0 to day 2 afterward in the local Bitcoin market and then declined until 10 days afterward. The results indicate that investors initially trade even more actively to adjust their positions in the local market in response to the local regulation announcement. But after 2 days, the overall trading activity in the local market drops significantly. Such a decrease in trading is not reverted even after 10 days, indicating that local regulation seems to have a lasting repressive impact on trading in the local market. Given that the global Bitcoin price has been generally unaffected by the local regulatory event, it seems investors simply migrated to the markets where the new regulation cannot be enforced and continued trading.

In columns (6)-(10) of Table 4, exploring whether trading responds differently to the two types of regulation event announcements, we find that similar to the results on Bitcoin prices, the local market does not react differently, and effect estimates of local regulation on trading activity are quite robust after we add the variable of regulation type. 


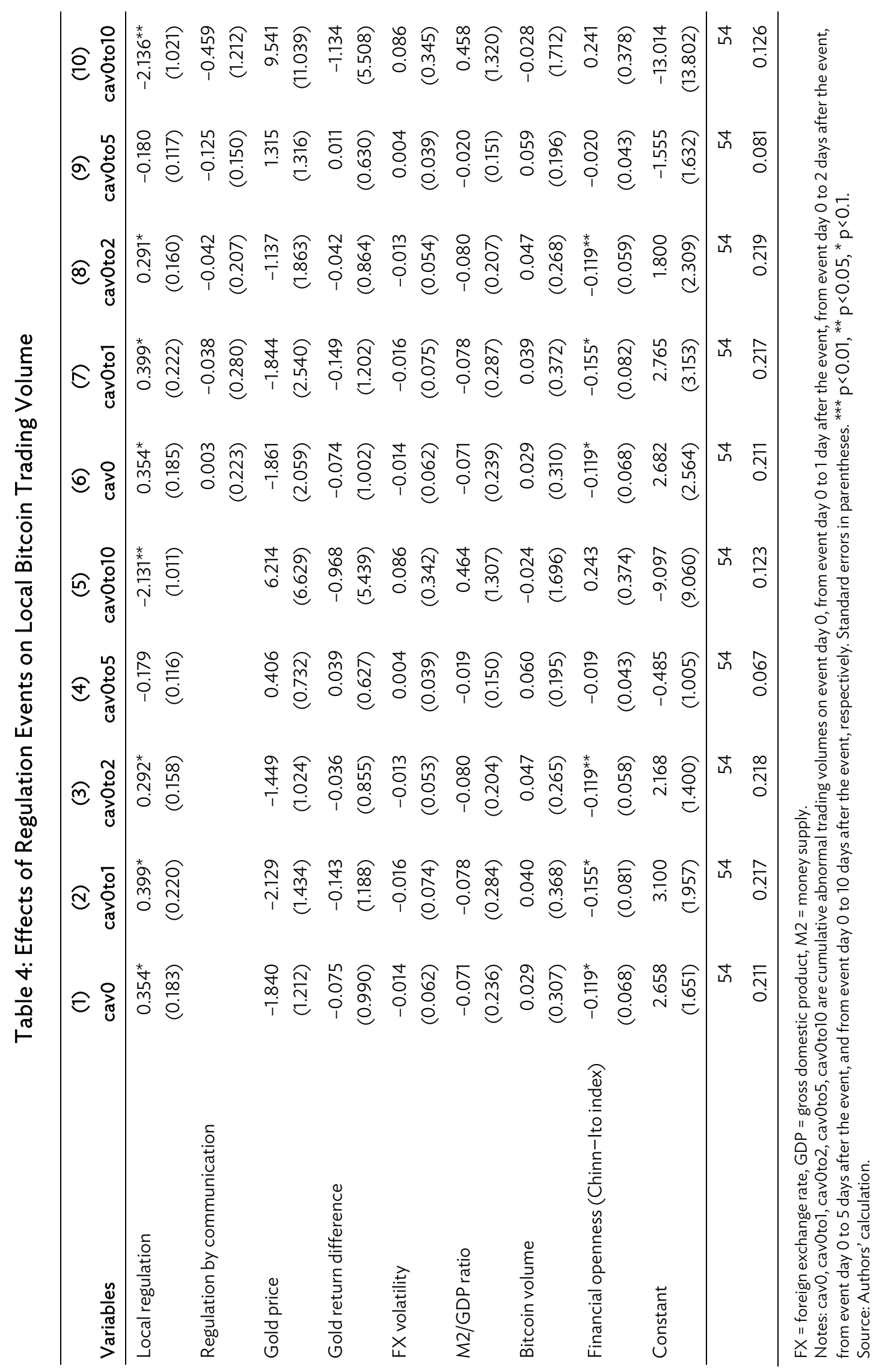


Table 4 results are visualized in Figure 7, which shows how local trading activity reacts to local regulations and nonlocal regulations. The permanent drop in local trading volumes following the regulatory event indicates that investors in Bitcoin markets are global and not confined to any local markets, even though most traded Bitcoins are denominated in local currencies. In fact, the trading volume in nonlocal markets moderately increased, reflecting the diffusion of the trading from the market affected by the new regulation to all other markets. Put together, Table 4 suggests that the local regulation would have no meaningful effects on global Bitcoin trading and prices, but it will drive investors out of the country.

Figure 7: Cumulative Average Abnormal Volume after the Regulation Events

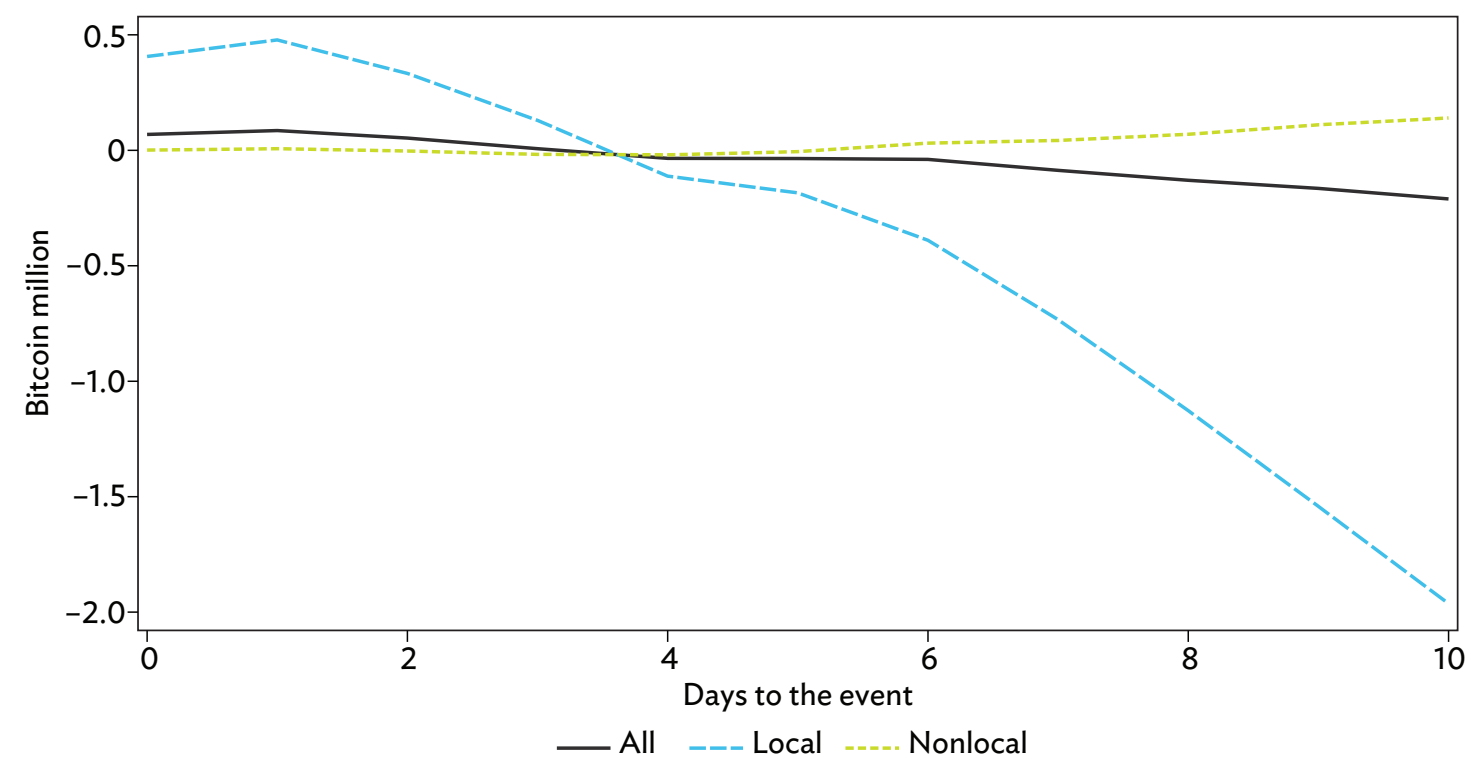

Source: Authors' calculation based on various data sources.

Other variables we include in the regressions to control for market friction and depth across different markets do not seem to significantly drive the difference of CAR or CAV after the regulation event. The variable for financial openness seems to have an opposite effect to local regulation, especially on Bitcoin trading volume.

To explore the role of financial openness, in Table 5 we empirically test whether the effect of regulation events varies with financial openness by including an interaction term between local regulation and financial openness (Chinn-Ito index). Investors in a relatively free and open market are expected to face lower transaction costs and barriers to asset diversification internationally. As expected, columns (6)-(10) of Table 5 show that the negative effect of regulation events on local Bitcoin trading activity is significantly mitigated in markets with higher financial openness. This suggests the adjustment costs borne by the investors in response to the local regulation should be smaller in more financially open economies. 


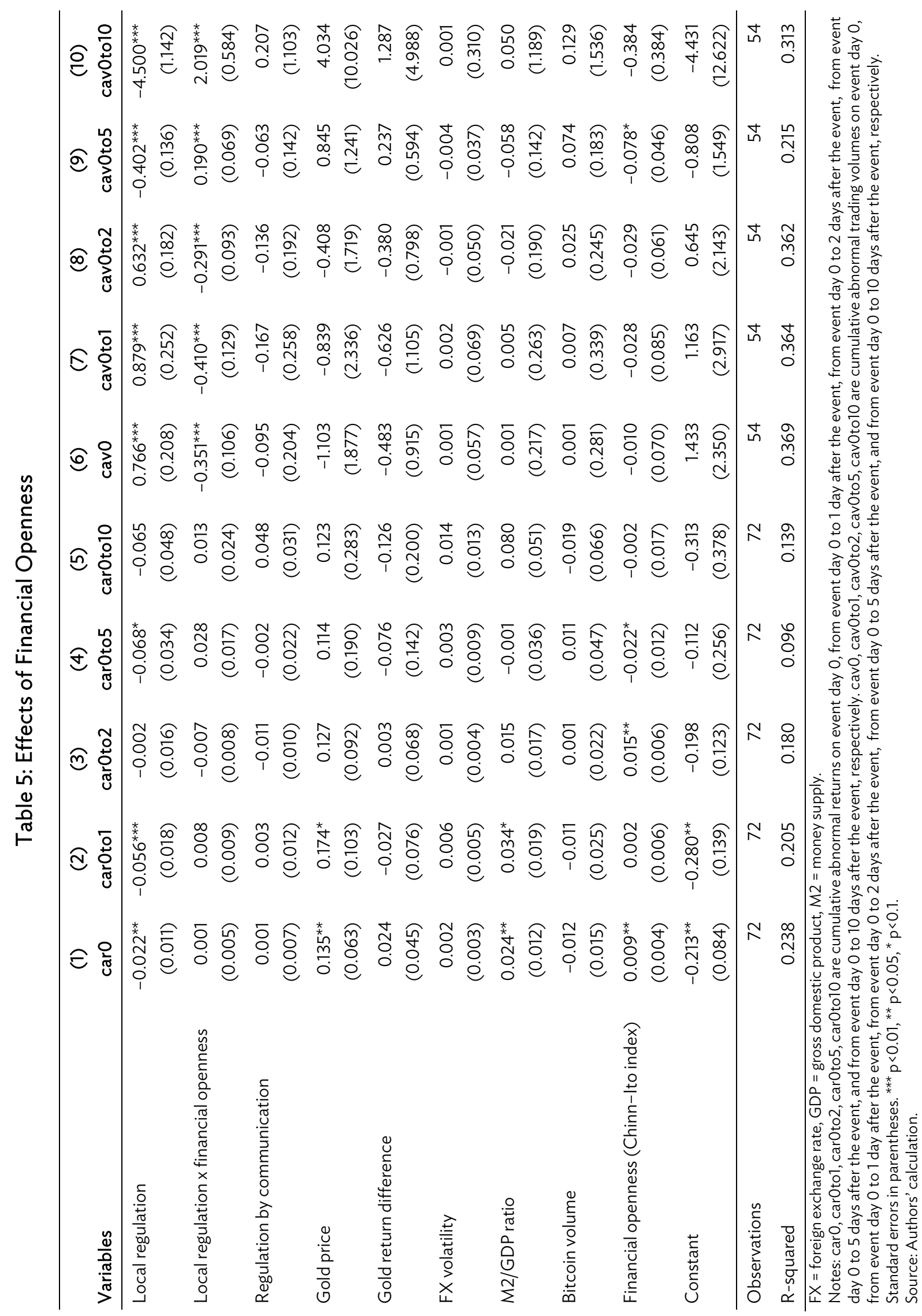




\section{CONCLUSION AND POLICY IMPLICATIONS}

The price of Bitcoin should be globally uniform if the global market is fully integrated. In practice, however, the local Bitcoin prices differ due to various market frictions. On the other hand, if the local Bitcoin markets are segmented, the price of Bitcoin will differ considerably across individual national markets, driven by respective local market dynamics. Therefore, the effect of local regulations would be significant and permanent.

Despite regulatory agencies in different jurisdictions actively regulating Bitcoin trading, little is known about how these regulations affect the global Bitcoin prices. With newly compiled information on local regulation events and the event study methodology, our empirical evidence shows that local regulation events drive down Bitcoin cumulative abnormal returns in the local market on the announcement day and the day after. Two days after the announcement, however, Bitcoin returns revert to normal patterns. This shows that the effect of local regulation is short-lived and the global Bitcoin markets are integrated.

Interestingly, local regulation events significantly increase local trading volume in the first 2 days, followed by significantly lower local trading activity, which lasted more than 10 days after the announcement. This implies that investors sold off in the local market in response to the negative local regulatory event and migrated elsewhere to evade regulation. Such local trading behavior combined with the short-lived local regulatory effect on the local price suggests the relatively high degree of integration in global Bitcoin markets. Cross-border arbitrage opportunities seem to disappear quickly following the local regulation events. Moreover, in markets with greater financial openness, the longrun repression effect on trading is mitigated. The results infer that there are ways to evade local regulations when financial markets are more open.

Overall, our findings suggest that investors consider Bitcoin as a global asset in that the value of Bitcoin is fundamentally identical across different markets: therefore, the Bitcoin price is globally determined and cannot be influenced over a longer horizon by individual markets. Our findings also imply that global Bitcoin markets are highly integrated and local price discrepancies are mostly due to market frictions particularly associated with the foreign exchange markets, rather than due to segmentation of local Bitcoin markets.

These findings are consistent with the view that it is a challenge for a regulator in a single country to regulate the price and trading activity of cryptocurrency determined by investors from the global network. A longer-term impact on trading volume shows that investors do not necessarily differentiate where they trade Bitcoin, despite different currency denominations in local markets. Market frictions associated with physical transactions and local currency denominations would explain the local price differences, but local regulations do not create abnormal returns that are beyond the cost of cross-border transactions. National policies cannot help contain market speculation for global Bitcoin prices. Nevertheless, local regulations can drive speculative investors out of the local market.

This paper contributes to the literature, first by adding new evidence to the factors determining Bitcoin prices by exploring the role of regulations in major Bitcoin markets; second, it helps understand the cross-market price discrepancy by incorporating the role of regulation events in local and global Bitcoin markets; third, in its policy implications, it shows that regulators need to collaborate to harmonize regulations across jurisdictions and foster the healthy development of the 
cryptocurrency market. Local regulation alone is insufficient to contain the high volatility and speculative attributes of the global Bitcoin markets. Regulatory cooperation would be essential to better safeguard financial stability and protect investors sometime in the future when and if the growth of cryptocurrency and market speculation present a risk to broader financial systems. 


\section{REFERENCES}

Al-Khazali, Osamah, Bouri Elie, and David Roubaud. 2018. "The Impact of Positive and Negative Macroeconomic News Surprises: Gold versus Bitcoin.” Economics Bulletin 38 (1): 373-82.

Balcilar, Mehmet, Elie Bouri, Rangan Gupta, and David Roubaud. 2017. "Can Volume Predict Bitcoin Returns and Volatility? A Quantiles-Based Approach.” Economic Modelling 64: 74-81.

Bernanke, Ben, and Kenneth Kuttner. 2005. "What Explains the Stock Market's Reaction to Federal Reserve Policy?” Journal of Finance 60 (3): 1221-57.

Blau, Benjamin M. 2018. "Price Dynamics and Speculative Trading in Bitcoin." Research in International Business and Finance 41: 493-99.

Böhme, Rainer, Nicolas Christin, Benjamin Edelman, and Tyler Moore. 2015. "Bitcoin: Economics, Technology, and Governance." Journal of Economic Perspectives 29 (2): 213-38.

Bouoiyour, Jamal, and Refk Selmi. 2015. "What Bitcoin Looks Like?” Annals of Economics and Finance 16 (2): 449-92.

Bouri, Elie, Peter Molnár, Georges Azzi, David Roubaud, and Lars Ivar Hagfors. 2017. "On the Hedge and Safe Haven Properties of Bitcoin: Is It Really More Than A Diversifier?" Finance Research Letters 20: 192-98.

Bouri, Ellie, Rangan Gupta, Aviral Kumar Tiwari, and David Roubaud. 2017. "Does Bitcoin Hedge Global Uncertainty? Evidence from Wavelet-Based Quantile-In-Quantile Regressions.” Finance Research Letters 23: 87-95.

Brandvold, Morten, Peter Molnár, Kristian Vagstad, and Ole Christian Andreas Valstad. 2015. "Price Discovery on Bitcoin Exchanges." Journal of International Financial Markets, Institutions \& Money 36 (C): 18-35.

Canepa, Francesco. 2018. "ECB Wants Banks to Segregate Any Virtual Currency Business." Reuters. 14 May. https://www.reuters.com/ article/us-ecb-policy-bitcoin/ecb-wants-banks-to-segregateany-virtual-currency-business-idUSKCN1IF168.

Ciaian, Pavel, Miroslava Rajcaniova, and d'Artis Kancs. 2016. "The Economics of Bitcoin Price Formation." Applied Economics 48 (19): 1799-815.

DeLong, J. Bradford, Andrei Shleifer, Lawrence Summers, and Roberts Waldmann. 1990. "Noise Trader Risk in Financial Markets." Journal of Political Economy 98 (4): 703-38.

Chinn, Menzie D., and Hiro Ito. 2006. "What Matters for Financial Development? Capital Controls, Institutions, and Interactions." Journal of Development Economics 81 (1): 163-92.

CryptoCompare. https://www.cryptocompare.com/.

Diamond, Douglas, and Robert Verrecchia. 1991. "Disclosure, Liquidity, and the Cost of Capital." Journal of Finance 46 (4): 1325-59. 
Dyhrberg, Anne Haubo. 2016a. "Bitcoin, Gold and the Dollar-A GARCH Volatility Analysis." Finance Research Letters 16: 85-92.

_ 2016b. "Hedging Capabilities of Bitcoin. Is It the Virtual Gold?" Finance Research Letters 16: 139-44.

Even-Tov, Omri. 2017. "When Does the Bond Price Reaction to Earnings Announcements Predict Future Stock Returns?" Journal of Accounting and Economics 64 (1): 167-82.

Flannery, Mark, and Aris A. Protopapadakis. 2002. "Macroeconomic Factors Do Influence Aggregate Stock Returns." The Review of Financial Studies 15 (3): 751-82.

Frijns, Bart, Ivan Indriawan, and Alireza Tourani-Rad. 2015. "Macroeconomic News Announcements and Price Discovery: Evidence from Canadian-U.S. Cross-Listed Firms." Journal of Empirical Finance 32: 35-48.

Gao, Pingyang. 2008. "Keynesian Beauty Contest, Accounting Disclosure, and Market Efficiency." Journal of Accounting Research 46 (4): 785-807.

Gau, Yin-Feng, and Zhen-Xing Wu. 2017. "Macroeconomic Announcements and Price Discovery in the Foreign Exchange Market." Journal of International Money and Finance 79: 232-54.

Gilbert, Thomas, Chiara Scotti, Georg Strasser, and Clara Vega. 2017. "Is the Intrinsic Value of a Macroeconomic News Announcement Related to Its Asset Price Impact?" Journal of Monetary Economics 92: 78-95.

Goh, Brenda. 2017. "Beijing Cryptocurrency Exchanges Told to Announce Trading Halt.” Reuters. 15 September. https:/in.reuters.com/article/bitcoin-china/beijing-cryptocurrency-exchangestold-to-announce-trading-halt-source-idINKCN1BQ1LN.

Grobm, Denis, and Dimitri Vayanos. 2002. "Equilibrium and Welfare in Markets with Financially Constrained Arbitrageurs.” Journal of Financial Economics 66 (2-3): 361-407.

Hansen, Stephen, and Michael McMahon. 2016. "Shocking Language: Understanding the Macroeconomic Effects of Central Bank Communication." Journal of International Economics 99 (S1): S114-S133.

J.P. Morgan Global Research. 2018. Decrypting Cryptocurrencies: Technology, Applications and Challenges. New York.

Kondor, Péter. 2012. "The More We Know about the Fundamental, the Less We Agree on the Price." The Review of Economic Studies 79: 1175-207.

Leuz, Christian, and Peter D. Wysocki. 2007. "Economic Consequences of Financial Reporting and Disclosure Regulation: What Have We Learned?" Chicago Booth working paper.

Merton, Robert C. 1987. "A Simple Model of Capital Market Equilibrium with Incomplete Information." Journal of Finance 42 (3): 483-510. 
Nadarajah, Saralees, and Jeffrey Chu. 2017. "On the Inefficiency of Bitcoin." Economics Letters 150: 6-9.

Pieters, Gina, and Sofia Vivanco. 2017. "Financial Regulations and Price Inconsistencies across Bitcoin Markets." Information Economics and Policy 39: 1-14.

Rigobon, Roberto, and Brian Sack. 2004. "The Impact of Monetary Policy on Asset Prices." Journal of Monetary Economics 51 (8): 1553-75.

Shleifer, Andrei, and Robert Vishny. 1997. "The Limits of Arbitrage." Journal of Finance 52 (1): 35-55.

Stavroyiannis, Stavros. 2018. "Diversification Benefits of the Bitcoin." SSRN Electronic Journal. $10.2139 /$ ssrn.3169818.

Tahrir, Habiba. 2018. "Bitcoin Only 'Masquerades' as a Currency: BIS Research Chief." CCN. 10 August. https://www.ccn.com/bitcoin-only-masquerades-as-a-currency-bis-research-chief/.

Yermack, David. 2013. “Is Bitcoin a Real Currency? An Economic Appraisal.” NBER Working Paper No. 19747.

Urquhart, Andrew. 2016. “The Inefficiency of Bitcoin.” Economics Letters 148: 80-82.

_. 2017. “Price Clustering in Bitcoin.” Economics Letters 159: 145-48.

Verrecchia, Robert. 2001. "Essays on Disclosure." Journal of Accounting and Economics 32 (1-3): 97180.

Viglione, Robert. 2015. "Does Governance Have a Role in Pricing? Cross-Country Evidence from Bitcoin Markets." http://dx.doi.org/10.2139/ssrn.2666243.

Wagner, Alexander, Richard Zeckhauser, and Alexandre Ziegler. 2018. "Company Stock Price Reactions to the 2016 Election Shock: Trump, Taxes, and Trade." Journal of Financial Economics 130 (2): 428-51. 


\section{Global Bitcoin Markets and Local Regulations}

This paper investigates how the introduction of regulations for local Bitcoin markets will shape prices and trading activities in six major trading markets that comprise $99 \%$ of global trading volume. It finds that local government regulations only have a short-lived impact on the Bitcoin price but discourage longer-term trading activities in local markets. The paper also finds that the repressive effect of domestic regulations on trading activities can be mitigated by domestic financial market openness. It documents consistent evidence that Bitcoin markets are globally integrated but international cooperation is essential to uphold market integrity.

\section{About the Asian Development Bank}

ADB is committed to achieving a prosperous, inclusive, resilient, and sustainable Asia and the Pacific, while sustaining its efforts to eradicate extreme poverty. Established in 1966, it is owned by 68 members -49 from the region. Its main instruments for helping its developing member countries are policy dialogue, loans, equity investments, guarantees, grants, and technical assistance. 